\title{
Main directions of popularization of electronic state and municipal services among rural population
}

\author{
Gulnara Krupina*, Niyaz Safiullin, Dzhaudat Faizrakhmanov, and Chulpan Kurakova
}

Kazan State Agrarian University, 420015 Kazan, Russia

\begin{abstract}
The paper touches upon the relevant issue connected with the processes of digital transformation of the modern economy of the country. It describes the current state of development of informatization of rural areas and provides data on the use of information and communication networks in households of the Russian Federation, including urban and rural settlements. The data on the skills of working with a personal computer are analyzed by types of settlements of the Russian Federation. It is concluded that it is necessary to improve the computer literacy of rural residents of the country. As an example, it is proposed to use educational resources for mastering digital skills. A comparative analysis of the use of the Internet by urban and rural residents, including during the provision of electronic state and municipal services, is carried out. The fact of the presence of a digital inequality in the use of the network between cities and the villages is established. The factors of the formation of the digital divide between urban and rural population when receiving state and municipal services in electronic form are determined. The main reasons for the refusal to use the Internet for remote interaction of rural residents with public authorities during the provision of public services are found. The measures for the popularization and expansion of the system for the provision of electronic state and municipal services among rural population are proposed. As additional measures, the authors give recommendations to use the premises of local self-government bodies in rural areas as free access points to the Unified Portal of State and Municipal Services of the Russian Federation. The main direction of popularizing electronic interaction between rural population and state authorities is to conduct specialized digital literacy courses when receiving state and municipal services. It is proposed to scale up these courses at the regional and federal levels.
\end{abstract}

\section{Introduction}

Nowadays state and municipal authorities use the capabilities of information and communication technologies, including the Internet, for effective interaction with citizens and organizations. For this purpose, federal and regional portals of state and municipal services, websites of state and municipal authorities, as well as local self-government are actively used. Today, electronic state and municipal services are a convenient and modern form for making an appointment with a doctor, paying for utility bills, submitting tax reports, etc.

The digitalization process covers both large cities and small settlements. However, it is necessary to state that all the achievements of informatization of rural settlements and municipalities are reduced to informing citizens, however the rural population itself does not have the skills to work with information technology. At the same time, the gap in the field of informatization between cities and small settlements, and primarily small rural settlements, is growing.

More than 20 thousand (90\%) of Russian municipalities has to work in the field of informatization by residual principle, as they are subsidized. A colossal gap has formed between large cities and rural settlements, which make up the overwhelming majority of Russian municipalities.

Table 1 presents in percents the data on the use of information and communication technologies by the urban and rural population of Russia for 2018 .

Table 1. Use of information technologies and information and telecommunication networks in households by type of settlement in Russia

\begin{tabular}{|c|c|c|c|c|c|}
\hline \multirow{1}{*}{} & $\begin{array}{c}\text { Number of } \\
\text { households } \\
\text { - total } \\
\text { thousand } \\
\text { units }\end{array}$ & \multicolumn{4}{|c|}{$\begin{array}{c}\text { of which having (percentage of total } \\
\text { households) }\end{array}$} \\
\cline { 3 - 6 } & & $P C$ & $\begin{array}{c}\text { Internet } \\
\text { access }\end{array}$ & $\begin{array}{c}\text { Internet } \\
\text { access } \\
\text { using a } \\
P C\end{array}$ & $\begin{array}{c}\text { Internet } \\
\text { Broadband } \\
\text { Access }\end{array}$ \\
\hline Total & 55413.5 & 72.4 & 76.6 & 69.0 & 73.2 \\
\hline City & 41808.3 & 76.2 & 79.7 & 73.4 & 77.3 \\
\hline Village & 13605.2 & 60.5 & 67.1 & 55.4 & 60.7 \\
\hline
\end{tabular}

The data characterizing the use of ICT in urban and rural areas show that the rural population is less provided with access to the Internet, including broadband. Only every second rural resident uses personal computer with

* Corresponding author: upravshp@yandex.ru 
Internet access, while more than $70 \%$ of urban residents use the Internet to realize its potential in personal and professional activities.

\section{Materials and methods}

The inability of rural population to freely receive, use and disseminate information is Russia-wide problem that affects the socio-economic state. In this regard, a digital divide arises, that is, a situation in which a certain category of citizens has limited opportunities to use modern information and communication technologies. Digital divide can arise both on a national scale and within a region or even a city. It is dangerous because it creates a competitive advantage among the wealthy over the poor. Thus, the poor do not participate in the development of digital economy and worsen their position. The terms "digital inequality" and "digital divide" are synonymous and can be used equally.

Table 2. Share of population with PC skills by the type of settlement, 2018

\begin{tabular}{|l|c|c|c|}
\hline & Total & \multicolumn{2}{|c|}{$\begin{array}{c}\text { Type of } \\
\text { settlement }\end{array}$} \\
\cline { 2 - 4 } & & City & Village \\
\hline $\begin{array}{l}\text { Use of a personal computer } \\
\text { in the last 12 months - total }\end{array}$ & 72.4 & 76.0 & 61.6 \\
\hline $\begin{array}{l}\text { Copy or move of a file or } \\
\text { folder }\end{array}$ & 34.5 & 37.8 & 24.6 \\
\hline $\begin{array}{l}\text { Use of copy and paste tool } \\
\text { to duplicate or move } \\
\text { information in a document }\end{array}$ & 22.4 & 25.5 & 13.0 \\
\hline Work with text editor & 41.1 & 45.3 & 28.4 \\
\hline $\begin{array}{l}\text { Work with spreadsheets } \\
\text { (for example, using data } \\
\text { functions such as filtering, } \\
\text { sorting, formulas, creating } \\
\text { charts, etc.) }\end{array}$ & 20.8 & 23.6 & 12.3 \\
\hline $\begin{array}{l}\text { Use of programs to edit } \\
\text { photo, video and audio files }\end{array}$ & 21.2 & 23.0 & 15.6 \\
\hline $\begin{array}{l}\text { Creation of electronic } \\
\text { presentations using special } \\
\text { programs (for example, } \\
\text { Power Point) }\end{array}$ & 8.2 & 8.9 & 6.0 \\
\hline $\begin{array}{l}\text { Connecting and installing } \\
\text { new devices }\end{array}$ & 9.8 & 11.5 & 4.9 \\
\hline $\begin{array}{l}\text { Self-writing software using } \\
\text { programming languages }\end{array}$ & 1.1 & 1.3 & 0.5 \\
\hline $\begin{array}{l}\text { File transmission between } \\
\text { computer and peripheral } \\
\text { devices (digital camera, } \\
\text { player, mobile phone) }\end{array}$ & 36.8 & 41.5 & 22.5 \\
\hline $\begin{array}{l}\text { Changing parameters or } \\
\text { software configuration } \\
\text { settings }\end{array}$ & 2.7 & 3.2 & 29.8 \\
\hline $\begin{array}{l}\text { Installing a new or } \\
\text { reinstalling an operating } \\
\text { system }\end{array}$ & & 3.1 & 1.3 \\
\hline $\begin{array}{l}\text { Sending Email with } \\
\text { Attached Files }\end{array}$ & & & \\
\hline Other activities & & & \\
\hline
\end{tabular}

The digital divide is closely related not only to the ability to access the Internet, but also to the skills of working with information technology tools. Table 2 provides a percentage comparison of PC skills of urban and rural populations.

According to Table 2, the rural population has a lower level of work with a personal computer. As statistics shows, currently only $26 \%$ of the working-age population of Russia has digital literacy (they can solve problems in a technologically rich environment). The digital literacy of the rural population requires further development. For this, the state should actively introduce educational courses with a focus on the rural population.

For example, 20.35 University and Russian IT companies have launched an educational resource "tsifrovayagramotnost.rf" (website for digital literacy education). With the help of this online portal, any resident of Russia will be able to learn the safe and effective use of digital technologies and services, learn about modern opportunities and threats of the digital environment, learn to observe digital hygiene and protect personal data by studying structured information in a micro-learning format for free.

At the moment, the users have access to the first pilot version of the project, which contains training videos and articles to develop basic digital skills for both beginners and advanced digital consumers. Starting next year, this portal will be filled with online lessons, tests and such auxiliary services as development trajectories, tests for self-assessment of literacy.

\section{Results}

The purpose of this project is to double the level of digital literacy of rural residents of Russia by 2024. By this time, it is planned that rural users will undergo a variety of training and testing of the studied material on the portal, moreover training programs will be posted for various categories of digital consumers - from beginners to advanced users.

The main directions for the elimination of the digital divide between rural and urban residents were proposed in the Federal Law of July 7, 2003 No. 126-FL "On Communication". The latest amendments to the law provide the organization of points of access to the network in settlements of 250 to 500 people and the organization of access to the Internet at a speed of at least 10 Mbit / s. In 2014, a ten-year contract for the provision of universal communication services was signed with Rostelecom.

Next, we consider the use of the Internet by urban and rural population in the Russian Federation in 2018. The data is presented in Figure 1.

Urban residents are still more active Internet users, with $66 \%$ of the rural population actively using the Internet. In most cases, the Internet is used for entertainment and communication. Only $21.8 \%$ of the rural population order goods and services online.

Urban-type settlements and villages prefer wireless Internet, for them it is convenient to use social networks, but it is not very profitable to access more "heavy" 
resources. The rural population has the opportunity to pay for Internet services, but they can not connect to it. There is no network in many rural educational institutions, libraries, and even post offices.

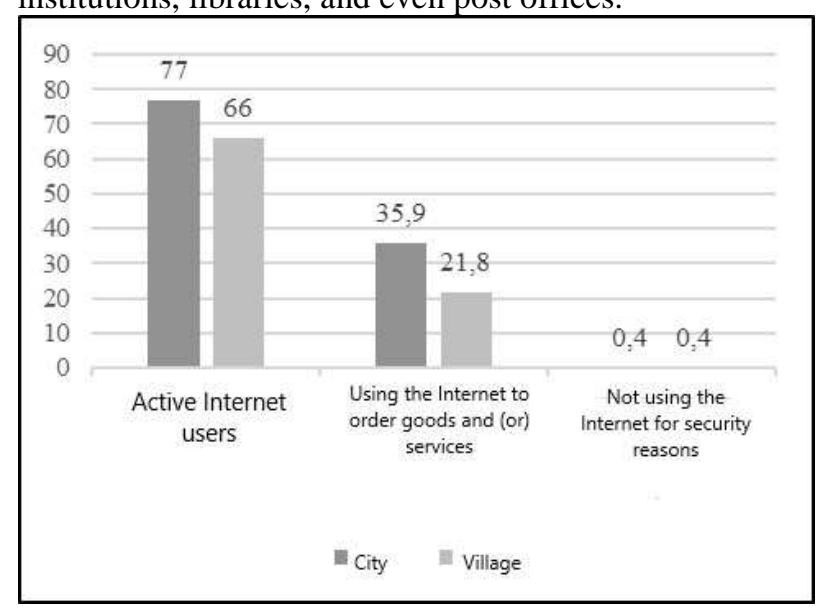

Fig. 1. Use of the Internet by urban and rural population

There are rural areas that are not covered by a highquality mobile network. In 1343 small towns and villages there is no possibility to make a voice call over the cellular network. In many settlements, modern communications have not yet been installed.

To eliminate the digital divide in Internet access points, free access is provided to more than 2,000 information resources of the state authorities of the Russian Federation, the Unified Portal of State and Municipal Services, as well as to the media that publish official regulatory legal acts.

One of the advantages of Internet is the ability to receive state and municipal services in electronic form. State (municipal) services are services that are provided to individuals and organizations at their request by federal executive bodies, executive bodies of state power of the constituent entities of the Russian Federation, governing bodies of state extra-budgetary funds of the Russian Federation or local administrations within their competence.

Today public services are provided in electronic form on the Portal of Public Services of the Russian Federation. It has the ability to submit electronic applications, receive notifications and extracts and pay state duties, taxes and fines.

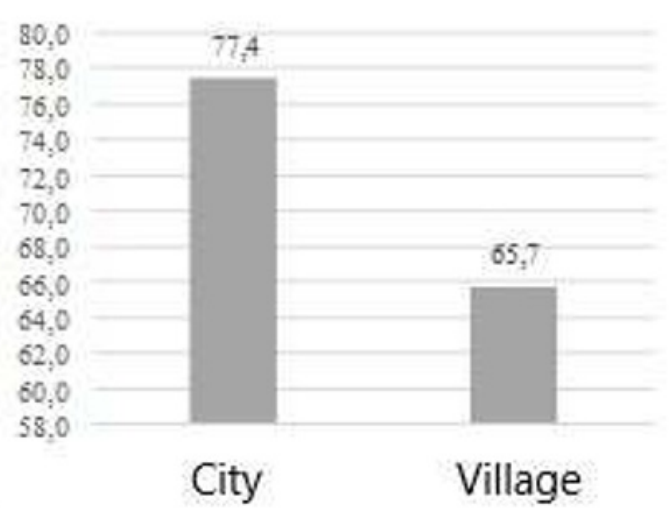

Fig. 2. Share of people using the Internet for receiving state and municipal services, $\%$
Figure 2 shows the data on the use of the system for the provision of electronic state and municipal services to the urban and rural population.

The source for the calculation of the indicator is the "Questionnaire for a sample survey of the population on the use of information technologies in information and telecommunication networks". Unfortunately, only $65.7 \%$ of the rural population uses the Internet to receive state and municipal services. This is also one of the indicators of the digital divide between rural and urban populations in Russia. In 2018, almost 56 million services were provided on the single portal of public services, which is $40 \%$ more than last year.

The portal currently contains more than 18 thousand different services of dozens of state institutions and departments for rural population.

The most popular services are:

1. Registration at the place of stay / residence

2. Information checking on enforcement proceedings

3. Checking tax liabilities

4. Payment for utility services

5. Enrollment in kindergarten

6. Vehicle registration

7. Checking and payment of traffic fines

8. Checking pension savings

9. Submission of a tax return

10. Registration of an international passport

The convenience of the electronic form of service provision is undeniable, especially for those who live in places far from the regional center. At a minimum, this is the provision of detailed information about what can be obtained and how, under what conditions, where to contact if necessary. It should be added that not all the settlements have all those state management and support bodies that are necessary.

For example, not all rural settlements have highquality medical care. In order to have a medical check, a rural person usually comes to the regional center, makes an appointment and waits for a doctor. In modern conditions, we can make an appointment online, and a person only has to come to the doctor at the appointed time. However, without sufficient knowledge of ICT, a person can not use the services that make his life easier.

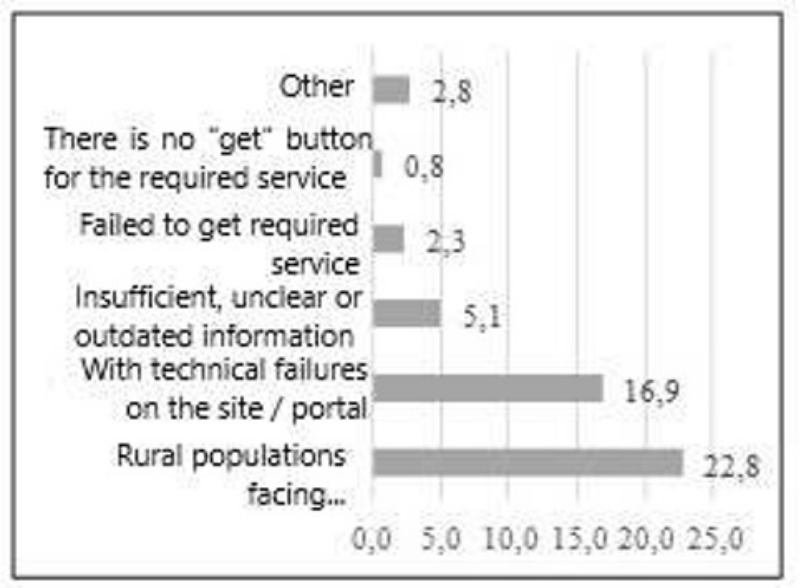

Fig. 3. Share of rural population facing problems to get state and municipal services through official websites and portals in the Russian Federation, \% 
In order to identify the factors that prevent the rural population from receiving state and municipal services in electronic form, Russian statistics service conducts a sociological study. The results are shown in Figure 3.

The revealed dispositions affecting the readiness of the population to use electronic services determine the desire of rural residents to use the system for providing electronic state and municipal services. $22.8 \%$ of the rural population faced problems in service provision.

This was mainly due to technical failures on the portal and insufficient and unclear information.

Figure 4 reveals the reasons for the refusal of the rural population to use the system of providing state and municipal services in electronic form.

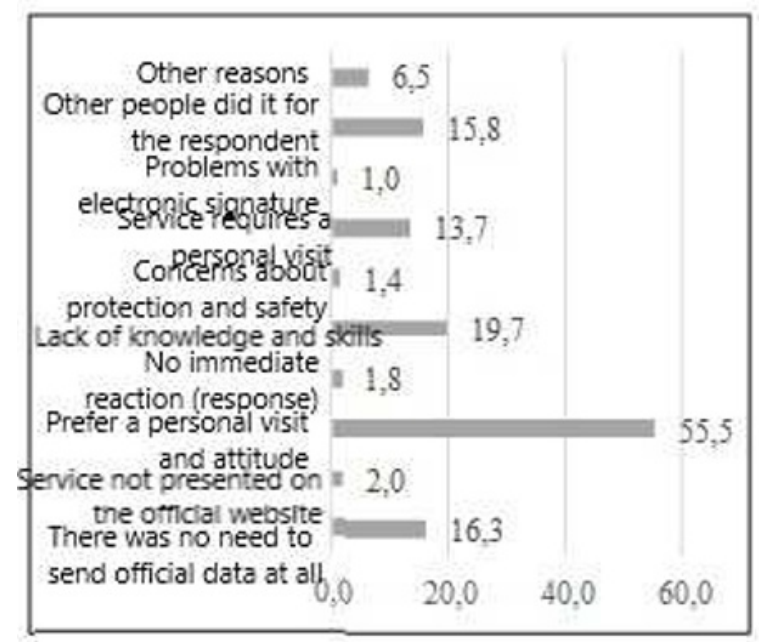

Fig. 4. Reasons for the refusal of the rural population from Internet use when receiving state and municipal services

\section{Discussion}

The rural population of the Russian Federation follows the established traditional model of communication with the authorities, despite the innovative forms of interaction actively introduced by the state.

The popularization and expansion of positive experience of the use of electronic environment for interacting with government agencies are relevant in the context of the data presented on the reasons of refuse from the Internet when receiving state and municipal services.

According to the federal target program "Electronic Russia (2002-2010)" and the Concept of reducing administrative barriers and increasing the availability of state and municipal services for 2011-2013, the infrastructure of public Internet access and services for the provision of state and municipal services was organized in rural areas. Such points operate in post offices, rural libraries and local government offices.

In addition, regional executive authorities and local self-government bodies providing state and municipal services are legally obliged to provide applicants with access to complete, relevant and reliable information on the provision of state and municipal services, including in electronic form.
In the buildings of the Executive Committees of rural settlements, it is necessary to place posters containing brief information:

- on the advantages of receiving state and municipal services in electronic form and the difference from traditional way;

- on the lists of state and municipal services available for receipt in electronic form;

- on the schemes for registration and identity verification when registering at unified and regional portals of public services.

It is recommended to place demos with changeable demopanels in the public reception room, informing citizens about:

- state and municipal services available for receipt in electronic form;

- the stages and channels of receiving state and municipal services in electronic form;

- the registration and leveling up the account at unified and regional portals of public services;

- identification when registering at unified and regional portals of public services;

- making payments at unified and regional portals of public services;

- other information materials aimed at informing citizens about the benefits of receiving state and municipal services in electronic form.

The next direction of the popularization of electronic public services provision is the introduction of training and educational courses as a part of digital literacy development of rural population.

The authors propose to develop a specialized course "Digital literacy receiving electronic state and municipal services." This course is an adaptation of digital literacy courses specifically for rural population and is aimed at developing initial competencies in the field of working with unified portal of public services. The course will cover the basic topics that are required to safely and efficiently use digital technologies and Internet resources to get services.

The course "Digital literacy receiving electronic state and municipal services" is relevant during the solution of problems of social adaptation of rural population to the modern information environment. Due to the training, they will get a general understanding of a personal computer, rules and safety measures when working in the Internet, learn how to type and format texts, handle files and folders, independently access the Internet, use state portals, websites and applications.

This course can be online on the basis of the educational resource "Tsifrovayagramotnost'.rf" or offline in rural libraries and schools. The teachers of the course can be representatives of higher and secondary vocational agricultural educational institutions, as they have a greater understanding of the specifics of rural life.

\section{Conclusion}

The process of digitalization of rural settlements and the training of rural population in information technology skills contributes to the diversification of local economy, 
the formation of expanded sources of income for villagers, the development of self-employment and the approach of urban living standards to the countryside. The implementation of the popularization directions will increase the level of loyalty of rural population to the system of electronic public services. It can be implemented at the local level of districts and scaled up at the level of a region and the country as a whole.

\section{References}

1. N.A. Safiullin, G.R. Valieva, D.I. Faizrahmanov, L.N. Savushkina, C.M. Kurakova, Quality assessment of electronic state and municipal services using the example of the ministry of agriculture of the Russian Federation, BIO Web of Conf., 17, $00143 \quad$ (2020) DOI: https://doi.org/10.1051/bioconf/20201700143

2. S.V. Ratner, The digital divide of Russian regions as a threat to socio-economic development of the country, National interests: priorities and security, 39 (2012)

3. A.E. Khvatov, A.S. Vatoropin, Factors preventing the population from receiving public services in electronic form, Management Issues, 3(46) (2017)

4. D.Ye. Dobrinskaya, T.S. Martynenko, Prospects for the Russian Information Society: Levels of the Digital Divide, RUDN Herald. Series: Sociology (2019)

5. S.G. Bylina, Regional features and determinants of the use of electronic services by the rural population, Problems of territory development, 5(97) (2018)

6. V.Ya. Akhmetov, R.N. Galikeev, Prospects for the socio-economic development of rural areas in the context of the digitalization of the economy, Bull. of Eurasian Sci., 6 (2019)

7. N.A. Safiullin, Evaluation of the effectiveness of the provision of state and municipal services based on PEST analysis, Bull. of Kazan State Agrarian University, 14(4-2) (56), 136-141 (2019) 